\title{
The beta puzzle revisited: A panel study of hedge fund returns
}

\author{
François-Éric Racicot* and Raymond Théoret \\ *University of Quebec (Outaouais), (UOO), 283 Alexandre Tache Boul., Gatineau, Quebec, \\ Canada J8X $3 \times 7$. \\ Tel: + 18195953900 ext. 1727, E-mail: francoiseric.racicot@uqo.ca \\ Received (in revised form): 15th February, 2007
}

François-Éric Racicot, PhD, holds a joint doctorate in Business Administration (Finance) from UQAM. He also holds an MSc in Economics (Econometrics) from University of Montreal where he also received his BSc in Economics (Quantitative Economics). He is Associate Professor of Finance at the Department of Administrative Sciences of the University of Quebec, Outaouais (UOO). He was Professor of Finance at the Department of Strategic Business of ESG-UQAM. He is a permanent member of the Laboratory for Research in Statistics and Probability (LRSP) and a research associate at the Chaire d'information financiere et organisationnelle located at ESG-UQAM. He is also a consultant in Financial Engineering for various financial institutions in Quebec. His research fields include the theory of fixed income securities, the theory of derivative products, the empirical analysis of hedge funds and project financial engineering. Presently, his research focuses on the development of new econometric techniques for correcting and detecting specification errors in financial models, especially in the context of estimating the alpha of hedge funds. This research should be useful, especially for improving the selection of hedge funds used in the construction of fund of funds. He has published many books in financial engineering used at the graduate levels in universities and also in financial institutions.

Raymond Théoret, PhD, holds a doctorate in Economics (financial economics) issued by the University of Montreal. He is Professor of Finance at l'École des Sciences de la Gestion (ESG) of the University of Quebec, Montreal (UQAM). He was previously Professor in financial economics at I'Institut d'Économie Appliquée located at HEC Montreal. He was an economic and financial consultant at various financial institutions in Quebec and the Secretary of Campeau Commission on the improvement of the situation of financial institutions in Montreal which led to the foundation of Institut de Finance Mathématique de Montreal. He has published many articles and many books on financial engineering, especially in the fields of numerical methods and computational finance. Moreover, he is the founder of DESS (finance) issued by UQAM and a co-founder of the Maitrise en finance appliquée at the same university. He teaches portfolio management theory and computational finance. His research focuses on modelling hedge fund returns, especially in its link with specification errors. He is an associate member of the Chaire d'information financière et organisationnelle located at ESG-UQAM.

Journal of Derivatives \& Hedge Funds, Vol. 13 No. 2, 2007, pp. 125-146 C 2007 Palgrave Macmillan Ltd $1753-9641 \$ 30.00$

\section{Practical applications}

This paper will add to the tools of the financial practitioner for estimating the conditional alphas and betas of individual hedge funds classified by strategy. Actually, the excess returns of individual funds within a strategy must be estimated in panel, our paper showing that the behaviour of individual funds sorted by strategy may differ greatly. Moreover, those returns must also be estimated by an instrumental econometric method to discard specification errors from the chosen multifactor model. We provide new instruments which are very relevant to account for the option-like dimensions of the hedge fund strategies. 


\section{Abstract}

Ferson and Schadt (1996) observed a beta puzzle in the mutual fund industry, which is a negative link between their beta and the market risk premium. The objective of this study is to verify if such a relation is present in the hedge fund industry. Our contribution is threefold. First, we use an instrumental variable method to estimate our conditional version of the Fama and French (FEF) model, conditional models being usually estimated by ordinary least squares. Secondly, we resort to a new set of performing instruments to estimate our conditional model: the higher moments of the risk factors that constitute the augmented version of the FEF model. Finally, we resort to a GMM panel procedure to estimate the excess returns of the HFR hedge funds pooled by strategy over the period 19972005. Our study reveals that there is generally no beta puzzle in the hedge fund industry. There is an apparent beta puzzle for the distressed securities and short seller strategies, but it seems rational for those strategies to increase their beta when the market risk premium is low: business opportunities are then much more important for them.

Journal of Derivatives \& Hedge Funds (2007) 13, 125-146. doi:10.1057/palgrave.jdhf.1850062

Keywords: specification errors; higher moment instruments; hedge funds; Fama and French model; n-moment CAPM; conditional CAPM; GMM-hm

\section{INTRODUCTION}

There is yet an unsolved beta puzzle in the financial literature. While studying the returns of mutual funds, Ferson and Schadt ${ }^{1}$ observed that these funds had a tendency to increase their conditional beta when the market risk premium decreases. According to them, the behaviour of the typical mutual fund is perverse and that gives way to the beta puzzle. Ferson and Schadt tried to explain this puzzle by the negative correlation between changes in conditional betas and change in net new money flows. Yet, cash holdings are positively correlated with net new money flows. Thus, when cash holdings are high, beta is low, a normal relation. Here, there is an endogeneity econometric problem that must be dealt with a robust instrumental variable (IV) estimator.

In this paper, we revisit the beta puzzle for a sample of HFR hedge fund indices and a sample of HFR individual funds pooled by strategy. Our contributions are the following. First, we resort, to perform our estimations, to a GMM estimator using as instruments the higher moments of the risk factors of the augmented Fama and French (F\&F) model, the basic model used in this study to do our estimation of returns. Because the choice of the conditional information is strictly an empirical matter, the estimation of conditional financial models requires resorting to IV methods. And as deplored by Watson, ${ }^{2}$ the choice of instruments is too often neglected in the financial econometric literature. We will show that the higher moments of the risk factors of our conditional model are relevant instruments to do the estimation of the coefficients related to endogenous variables, which, as just said, create problems in conditional model. We will call this new form of GMM: the GMM-hm.

Secondly, we will do panel estimations of the hedge funds pooled by strategy to study the relation between the conditional beta and the risk premium. Obviously, even if we pool hedge funds by strategy, these groups remain heterogeneous due to the relative leeway of a portfolio manager. Panel estimation will allow us to take care of the fixed effects present in each 
group but also of the interaction between funds in each group by performing estimations using cross-section SUR. ${ }^{3}$ Really, hedge funds of a specific strategy are in interaction, be it only because they are confronted to a common environment.

This paper is organised as follows. The next section presents the innovative instruments used in this study, which are the higher moments of the risk factors, the ingredients to our GMM$\mathrm{hm}$ estimations. In the subsequent section, we develop the conditional model required to study the beta puzzle observed by Ferson and Schadt. ${ }^{1}$ In the penultimate section, we estimate these models using the HFR indices and HFR individual hedge funds grouped by strategies over the period 1997-2005 and we analyse the results. The final section concludes.

\section{THE CHOICE OF INSTRUMENTS ${ }^{4-7}$}

The basic model of this paper is the augmented version of the F\&F model. We will modify this model in the next section in order to estimate a conditional form of this model that allows studying the beta puzzle.

The augmented $F \& F^{8-10}$ model is a purely empirical model which may be written as:

$$
\begin{aligned}
R_{p t}-R_{f t}= & \alpha+\beta_{1}\left(R_{m t}-R_{f t}\right)+\beta_{2} S M B_{t} \\
& +\beta_{3} H M L_{t}+\beta_{4} U M D_{t}+\varepsilon_{t}
\end{aligned}
$$

with $R_{p t}-R_{f t}$ the excess return of a portfolio, $R_{f t}$ being the risk-free return; $R_{m t}-R_{f t}$ the market risk premium; $S M B$ a portfolio which mimics the 'small firm anomaly', which is long in the returns of selected small firms and short in the returns of selected big firms; $H M L$ a portfolio which mimics the 'income stock anomaly', which is long in returns of stocks of selected firms having a high (book value/market value) ratio (income stocks) and short in selected stocks having a low (book value/market value) ratio (growth stocks); UMD a portfolio which mimics the 'momentum anomaly', which is long in returns of selected stocks having a persistent upper trend and short in stocks having a persistent downward trend; $\varepsilon_{t}$ the innovation of the equation.

To explain the return of a stock or of a portfolio of stocks, the F\&F model adds to the unique factor retained by the CAPM, the market risk premium, three other factors which are assumed to represent market anomalies: the small firm anomaly, the book value to market value anomaly and the momentum anomaly. ${ }^{11-13}$ Subsequently, the anomalies of the F\&F model were viewed as real risk factors.

According to Capocci and Hübner, ${ }^{14}$ a positive sign for $S M B$ in equation (1) would indicate that a portfolio manager, here a hedge fund, prefers the stocks of small firms over the stocks of larger ones, what is usually the case for hedge funds. Moreover, a positive sign for the variable $H M L$ would be symptomatic of a preference for stocks with a high bookto-market value ratio over stocks with a low book-to-market value ratio, what is also a frequent preference in the hedge fund industry. Finally, a positive sign for the variable UMD indicates that a hedge fund follows the market trend and a negative sign, that it is a 'contrarian', what is the case for some very specialised strategies like the distressed securities one. Incidentally, the factor UMD does not seem to be important in the hedge fund industry. ${ }^{15}$

We postulate that equation (1) contains specification errors. These errors might be due to multiple causes but the main plausible ones may be the omission of relevant variables, the 
aggregation level of the data or simply an incorrect functional form. ${ }^{16,17}$ In this study, we relate these errors to an aggregation bias and to the neglect of the conditioning information.

Following these errors, the risk factors become endogenous and the condition of orthogonality between these factors of risk and the innovation term in equation (1) is violated: the estimators of the coefficients of equation (1) are no longer unbiased nor consistent. To purge these coefficients from these biases, we must regress in a first pass the independent variables on IVs. The estimated method used in this paper is the GMM. The problem lays in the judicious choice of these instruments.

As we said before, it is difficult to find valuable instruments for the excess returns of the mimicking portfolios. Being long in some stocks and short in others, their cash flows are actually similar to those of hedge funds. Higher moments of returns, like asymmetry and kurtosis, might have a significant influence on these returns. This suggests the use of higher moments of the variables on the RHS of equation (1) as IVs. An econometric theory is indeed in construction on this subject. Following Durbin ${ }^{18}$ and $\mathrm{Pal},{ }^{19}$ Dagenais and Dagenais ${ }^{20}$ showed that higher moments of independent variables of a regression might be valid instruments to remove errors-invariables, and more generally specification errors. Racicot $^{21-24}$ transposed this method to the estimation of asset pricing models. But instead of defining higher moments as in these papers, we will adopt in this section a method more akin to asset pricing theory that defines higher moments of returns as powers of these returns.

The method of asset pricing based on higher moments is not new. Samuelson, ${ }^{25}$ Rubinstein ${ }^{26}$ and Kraus and Litzenberger ${ }^{27}$ put the foundations of the three-moment and four- moment CAPM. The three-moment CAPM integrates asymmetry of returns in the analysis, while the four-moment CAPM adds kurtosis.

The n-moment CAPM can be written as follows $^{28-30}$ :

$$
\begin{aligned}
R_{i}-R_{f}= & \alpha_{0}+\alpha_{1}\left(R_{m}-R_{f}\right)+\alpha_{2}\left(R_{m}-R_{f}\right)^{2} \\
& +\alpha_{3}\left(R_{m}-R_{f}\right)^{3}+\ldots \\
& +\alpha_{n-1}\left(R_{m}-R_{f}\right)^{n-1}
\end{aligned}
$$

A test on $\alpha_{2}$ is a test on skewness preferences in asset pricing and a test on $\alpha_{3}$, a test on kurtosis preferences, and so on. The higher moments are consequently powers of returns in this approach. We therefore use a financial theory, the n-moment CAPM, to give an object to the method of Dagenais and Dagenais ${ }^{20}$ for correcting errors-in-variables. Let us return to the variable $S M B$, which we want to correct for the problem of absence of orthogonality with the innovation. In the first pass of the regression, this variable will be regressed on:

$$
S \hat{M} B_{t}=f\left(F_{i t-1}, F_{i t}^{2}, F_{i t}^{3}, \ldots, F_{i t}^{5}, \ldots\right)
$$

where $F_{i}$ are the variables in the RHS of the equation of $\mathrm{F} \& \mathrm{~F}$ (equation 1) including $S M B$. They stand for the higher moments of these variables. $F_{i t}^{2}$ stands for the skewness of factor $F_{i}$; $F_{i t}^{3}$, for its kurtosis, and so on. The variables appearing on the RHS of equation (3) will thus serve as IVs in our GMM estimations to revisit the beta puzzle.

\section{A CONDITIONAL VERSION OF THE F\&F MODEL TO STUDY THE BETA PUZZLE}

To see if there is a beta puzzle, we would formulate a conditional version of the F\&F model (equation 1). The conditional CAPM on which this version is based is due to Ferson and Schadt, ${ }^{1}$ Christopherson et al. ${ }^{31}$ More recently, 
Ferson and Qian ${ }^{32}$ revisited this model. Since hedge funds follow dynamic strategies, their alpha and beta are conditional upon public information. In this study, we are more interested in the conditional beta but we will also condition the alpha on public information.

Let us assume that a Fund has public information on a variable designated by $I_{t}$. On time $t$, it knows $I_{t-1}$. The Jensen alpha and the beta are conditional on this public information, that is:

$$
\begin{aligned}
& \alpha_{t}=\alpha_{0}+\varphi_{0} I_{t-1} \\
& \beta_{t}=\beta_{0}+\omega_{0} I_{t-1}
\end{aligned}
$$

If we assume that $I_{t}$ follows a martingale process, we may write:

$$
E\left(I_{t} / \Omega\right)=I_{t-1}
$$

with $\Omega$ the information set. The variable $I_{t-1}$ is thus the best predictor of $I_{t}$.

In equations (4) and (5), $I_{t-1}$ is written in deviation from its mean. The parameters $\alpha_{0}$ and $\beta_{0}$ are the nonconditional alpha and beta. Substituting equations (4) and (5) in equation (1), we get:

$$
\begin{aligned}
R_{p t} & -R_{f t}=\alpha_{0}+\varphi_{0} I_{t-1}+\beta_{0}\left(R_{m t}-R_{f t}\right) \\
& +\omega_{0}\left(R_{m t}-R_{f t}\right) I_{t-1}+\beta_{1} S M B_{t}+\beta_{2} H M L_{t} \\
& +\beta_{3} U M D_{t}+\varepsilon_{t}
\end{aligned}
$$

The choice of public information $I_{t-1}$ for estimating equation (7) is obviously an empirical matter. As suggested by Christopherson et al. ${ }^{31}$ and Ferson and Qian, ${ }^{32}$ we tried several financial and macroeconomic variables to play the role of conditioning information. Among them, we have market trend, inflation, the growth of industrial production, the dividend yield of stock indices like the S\&P500, the term structure of interest rates and various indicators of credit risk like the spread between BAA and AAA corporate bond returns. We finally retained the following empirical specification for equation (4):

$$
\alpha_{t}=\alpha_{0}+\varphi_{0} t b_{t-1}
$$

with $\alpha_{0}$, the unconditional alpha, and $t b$, the American three-month Treasury bill rate.

An increase in the interest rate might be perceived as good news or bad news by hedge funds. If this increase is seen as a forthcoming deterioration of the stock market trend or as an indicator of inflation, that is bad news. But for hedge funds which follow call-like strategies, that might be good news. The sign of $\ddot{o}_{0}$ is thus indeterminate in equation (8).

Let us now consider the empirical version of equation (5), that is the equation of conditional beta. Since we want to verify if the beta puzzle is present in the hedge fund industry, we will introduce the risk premium in the equation of the conditional beta. The normal relation between the conditional beta and the market risk premium should be positive. Really, if the market risk premium increases, that should induce hedge funds to bear more risk, that is to increase their beta. Nevertheless, if there is a beta puzzle, the relation between the beta and the risk premium will be negative, a perverse relation to use the terms of Ferson and Schadt. ${ }^{1}$ We will see that there might be a beta puzzle for some hedge funds following very specialised strategies like the distressed securities one but that this puzzle may be solved easily due to the specific character of these strategies.

We thus write the empirical version of equation (5) like this:

$$
\begin{aligned}
\beta_{t}= & \beta_{0}+\theta_{1}\left(R_{m t-1}-R_{f t-1}\right) \\
& +\theta_{2}\left(R_{m t-1}-R_{f t-1}\right)^{2}
\end{aligned}
$$


with $\left(R_{m t-1}-R_{f t-1}\right)$, the market risk premium lagged on period. We also introduced in this equation of the conditional beta, the square of the market risk premium as an indicator of stock market volatility. An increase of market volatility should usually induce hedge funds to bear less risk, and therefore to decrease their beta, but it remains that an increase in market volatility might be welcomed by some hedge fund strategies whose hedging activities are particularly important. Moreover, according to Treynor and Mazuy, ${ }^{33}$ the squared risk premium might serve to detect good or bad market timing, a good market timing being associated to a positive sign for this variable. The sign of the squared market risk premium is thus theoretically indeterminate in equation (9).

The empirical counterpart of equation (7), obtained by substituting equations (8) and (9) in equation (1), is thus:

$$
\begin{aligned}
R_{p t}-R_{f t}= & \alpha_{0}+\beta_{0}\left(R_{m t}-R_{f t}\right)+\beta_{2} S M B_{t} \\
& +\beta_{3} H M L_{t}+\beta_{4} U M D_{t}+\varphi_{0} t b_{t-1} \\
& +\ldots+\theta_{1}\left(R_{m t}-R_{f t}\right) \\
& \times\left(R_{m t-1}-R_{f t-1}\right) \\
& +\theta_{2}\left(R_{m t}-R_{f t}\right) \\
& \times\left(R_{m t-1}-R_{f t-1}\right)^{2}+\varepsilon_{t}
\end{aligned}
$$

where the conditioning variables $t b_{t-1}$, $\left(R_{m t-1}-R_{f t-1}\right)$ and $\left(R_{m t-1}-R_{f t-1}\right)^{2}$ are expressed in deviation from their mean.

\section{EMPIRICAL RESULTS AND ANALYSIS}

\section{Sample description}

This study is based on two samples: the sample of the HFR indices and the sample of individual HFR funds classified by strategies. Statistical information on these samples appears in Tables 1 and 2. Our observation period of the monthly returns of these hedge funds runs from January 1997 to December 2005, for a total of 108 observations. The risk factors which appear in the F\&F equation - that is the market risk premium and the three mimicking portfolios: $S M B, H M L$ and UMD - are for their part drawn from French's website. ${ }^{34}$ We used as instruments, besides the lagged endogenous variables and the higher moments of the risk factors, the Chen-Roll-Ross ${ }^{35}$ factors as suggested by Watson ${ }^{2}$ : the industrial production and the consumer price index expressed in monthly and annual growth rates; the spread between long- and short-term bond returns; the spread between BBB and AAA corporate bond returns and the dividend yield of the S\&P500. These factors are drawn from the databases of the Federal Reserve Bulletin and the Federal Reserve Bank of St-Louis.

\section{A first glance at the data \\ The sample of HFR indices}

Table 1 gives the descriptive statistics of the HFR indices over the period 1997-2005. This period was plagued by three major financial crises: (i) the Asian financial crisis (1997); (ii) the Russian/LTCM ${ }^{36}$ crisis (1998); (iii) the bursting of the high-tech market bubble (2000). Our period of analysis is therefore rich in major stock market corrections. In spite of these market collapses, Table 1 reveals that the HFR hedge funds performed very well during this period. The mean monthly return of these indices was 0.88 per cent over this period, for an annual rate of 10.6 per cent. That rate is higher than the annual mean return of the S\&P500 over the same period, which was 8.6 per cent. The low 
Table 1: Descriptive statistics of the HFR indices returns, 1997-2005

\begin{tabular}{lcccccccc}
\hline & Mean & Median & s.d. & MAX & MIN & Skew & Kurtosis & CAPM-beta \\
\hline Distressed securities & 0.95 & 1.00 & 1.82 & 5.34 & -8.88 & -1.38 & 10.26 & 0.21 \\
Emerging & 1.19 & 1.77 & 4.82 & 15.75 & -22.07 & -0.97 & 7.57 & 0.71 \\
Equity hedge & 1.10 & 1.18 & 3.07 & 11.54 & -7.42 & 0.35 & 4.24 & 0.52 \\
Equity market neutral & 0.66 & 0.52 & 1.16 & 3.88 & -3.90 & 0.04 & 5.33 & 0.03 \\
Equity non hedge & 1.10 & 1.44 & 4.65 & 12.50 & -15.52 & -0.27 & 3.95 & 0.85 \\
Event driven & 1.00 & 1.14 & 2.18 & 5.93 & -9.81 & -1.21 & 7.89 & 0.36 \\
Fund of funds & 0.72 & 0.68 & 1.48 & 5.46 & -6.09 & -0.24 & 7.41 & 0.20 \\
Macro & 0.76 & 0.80 & 2.04 & 6.24 & -4.27 & 0.22 & 3.36 & 0.16 \\
Market timing & 1.02 & 0.91 & 2.34 & 6.91 & -3.20 & 0.18 & 2.28 & 0.37 \\
Short seller & 0.33 & 0.23 & 7.13 & 26.43 & -21.00 & 0.43 & 5.80 & -1.22 \\
& & & & & & & & 5.81 \\
Mean of indices & 0.88 & 0.96 & 3.07 & 10.00 & -10.22 & -0.28 & 5.82 & 0.22 \\
Weighted composite & 0.95 & 0.96 & 2.32 & 7.62 & -8.31 & -0.27 & 4.91 & 0.41 \\
S\&P500 & 0.72 & 0.93 & 4.64 & 9.78 & -14.44 & -0.48 & 3.23 & 1.00 \\
\hline
\end{tabular}

${ }^{a}$ The statistics appearing in this table are computed on the monthly returns of the HFR indices over the period running from January 1997 to December 2005. The weighted composite index is computed over the whole set of the HFR indices. The CAPM beta is estimated using the simple market model, that is:

$R_{i t}-R_{f t}=\alpha+\beta\left(R_{m t}-R_{f t}\right)+\varepsilon_{i t}$,

where $R_{i}$ is the return of the index $i, R_{m}$ is the S\&P500 return, $R_{f}$ is the riskless rate and $\varepsilon_{i}$ is the innovation.

performers over this period were the short sellers and the equity market neutral indices, whereas the high performers were the emerging markets, the equity hedge and nonhedge indices.

Moreover, the standard deviation of the returns differs greatly from one index to the other. The standard deviation of the returns of the indices is generally below one of the S\&P500 index except for the short seller index that incidentally has the lowest mean return over the period of analysis. As expected, the equity market neutral index has the lowest standard deviation but it still performed relatively well in spite of its low volatility.
Several researchers argue that the strategies followed by hedge funds are similar to option-based strategies. And effectively, Table 1 reveals that hedge fund strategies are actually similar to hedged option strategies, like the covered call and protective put ones. Similarly to the hedge fund indices, these option-based strategies have a beta which is quite low, of the order of 0.6 for at-the money options, and may yet offer all the same quite high returns which approximate those shown in Table 1. ${ }^{37,38}$ Furthermore, the nonhedged option-based strategies might give a mean return which is much higher than those ones 
of Table 1 but at the cost of a much higher beta of the order of 7 . For instance, a plain vanilla call, which is at-the-money might have a beta equal to 8 .

Plain vanilla puts have a negative expected return. That may explain the low mean return of the short seller index over the period of analysis. Incidentally, the CAPM beta of the short seller index, equal to -1.22 , is negative and quite high in absolute value over the period of analysis. According to the CAPM, the excess return of a portfolio having a negative beta should be low and even negative and that is the case of the short seller index. Another index that has a very low beta on Table 1 is the equity market neutral index and its mean return is among the lowest in conformity with the CAPM.

Furthermore, according to Table 1, the composite index of hedge funds has more kurtosis than the market one, a characteristic shared by almost every strategy. A high kurtosis means that rare or extreme events are more frequent than in a normal distribution and that nonlinearities of payoffs are very present. Once more, we may relate these statistics to those associated to the cash flows of option-based strategies. They have a relatively low standard deviation but a high degree of kurtosis in comparison with the returns of the market index.

\section{The sample of HFR individual hedge funds classified by strategies}

Table 2 gives some descriptive statistics for individual HFR hedge funds classified by strategies over the period 1997-2005. ${ }^{39}$ We notice that the mean returns of the strategies are quite comparable to those of the indices but that the standard deviations of the strategy returns are higher. That is because there is obviously less diversification for the individual funds than for the indices. Incidentally, there are five strategies over 11 that have a standard deviation of returns higher than the S\&P500, which might indicate that the individual hedge funds are not so hedged than usually thought. There is more diversification on the side of the funds of funds whose standard deviation is one of the lowest among strategies reported on Table 2. This table also reveals that the maximum and minimum returns obtained by individual funds are much higher, in absolute value, than in the case of the indices. For instance, the minimum return over the period of analysis, that is ( 88.5 per cent), was observed for the event-driven strategy whose maximum return, also the highest over strategies, was 54.3 per cent, rates obviously very extreme. Similar maximum and minimum returns were observed for the emerging market strategy. The alternative investments may obviously be much riskier than the traditional ones even when viewed on the basis of a traditional measure of risk: the standard deviation. Hedging operations do not necessarily decrease this measure of risk. Really, it is often difficult to distinguish hedging operations from speculative ones.

We also note in Table 2 that the kurtosis of returns is generally higher for the individual funds than for the indices. Indeed, there is some evidence in the literature that diversification reduces kurtosis. But we must be cautious on that matter. Funds of funds have some degree of diversification. Nonetheless, at 8.39, the kurtosis of their returns is one of the highest of Table 2 over the period of analysis. Obviously, rare events seem more frequent for the individual funds than for the indices that are not tradable. 
Table 2: Descriptive statistics of the returns of the individual HFR funds classified by strategies, $1997-2005^{a}$

\begin{tabular}{lcccccccc}
\hline & Mean & Median & s.d. & MAX & MIN & Skew & Kurtosis & $\begin{array}{r}\text { Number } \\
\text { of funds }\end{array}$ \\
& & & & & & & & \\
\hline Distressed securities & 0.97 & 0.90 & 1.49 & 37.93 & -18.13 & -0.02 & 7.27 & 23 \\
Emerging & 1.39 & 1.56 & 8.21 & 81.76 & -64.59 & -0.66 & 11.26 & 42 \\
Equity hedge & 1.16 & 0.93 & 5.04 & 60.81 & -34.52 & 0.40 & 7.12 & 99 \\
Equity market neutral & 0.58 & 0.51 & 2.49 & 18.09 & -24.80 & -0.06 & 4.82 & 26 \\
Equity non hedge & 1.28 & 1.35 & 6.06 & 76.19 & -61.54 & 0.00 & 5.43 & 47 \\
Event driven & 0.90 & 0.95 & 3.22 & 88.47 & -54.30 & -0.81 & 9.07 & 45 \\
Fund of funds & 0.82 & 0.74 & 2.19 & 27.45 & -28.08 & -0.24 & 8.39 & 101 \\
Macro & 0.85 & 0.65 & 3.81 & 44.27 & -24.84 & 0.53 & 5.62 & 26 \\
Managed futures & 0.86 & 0.50 & 5.50 & 40.83 & -27.00 & 0.41 & 4.23 & 70 \\
Market timing & 1.01 & 0.67 & 3.77 & 27.10 & -14.50 & 0.68 & 4.83 & 8 \\
Short seller & 0.19 & -0.26 & 8.88 & 47.32 & -51.86 & 0.22 & 5.86 & 6 \\
& & & & & & & & \\
Mean of funds & 0.91 & 0.77 & 4.61 & 50.02 & -36.74 & 0.04 & 6.72 & \\
Weighted composite & 0.95 & 0.96 & 2.32 & 7.62 & -8.31 & -0.27 & 4.91 & \\
S\&P & 1.29 & 1.14 & 5.28 & 23.30 & -14.02 & 0.48 & 6.37 & \\
\hline
\end{tabular}

${ }^{a}$ For each strategy, we selected, in the HFR database, all the funds whose sample begins in January 1997 or before.

\section{Methods of estimation and the empirical choice of instruments}

In this paper, we will use two methods to estimate our models: the OLS (ordinary least squares) and the GMM (generalised method of moments). ${ }^{40,41}$ The GMM method will be used to purge the estimated coefficients from their eventual specification errors. The choice of instruments was discussed in the previous section. As noted by Watson, ${ }^{2}$ empirical verifications of asset pricing models which use the GMM method generally neglect the problem of the choice of instruments required by this method. Watson limits his choice to the lagged variables of the F\&F model and to the
Chen-Roll-Ross ${ }^{35}$ factors, which are essentially financial and macroeconomic variables: credit risk spreads, term structure of interest rates, dividend yields of stock market indices, inflation rate, prices of commodities, growth of industrial production, exchange rates, and so on. As said previously, we innovate in this study by using as additional instruments the higher moments of the four risk factors of the F\&F model. These moments are powers of these risk factors. We incorporate in our GMM instruments these higher moments up to the fifth order. This method is labelled the GMM-hm method.

In Table 3, we compare the $R^{2}$ and the adjusted $R^{2}$ of the risk factors of the F\&F model, 
Table 3: $R^{2}$ of the regressions of the risk factors of the Fama and French model on classical instruments and higher moment instruments ${ }^{a}$

\begin{tabular}{llllll}
\hline & \multicolumn{2}{l}{ Classical instruments } & & \multicolumn{2}{c}{ Classical and higher moment instruments } \\
\cline { 2 - 3 } & $R^{2}$ & $R^{2}$ adj. & & $R^{2}$ & $R^{2}$ adj. \\
\hline $\mathrm{mkt}-\mathrm{rf}$ & 0.07 & 0.01 & 0.86 & 0.84 \\
$\mathrm{smb}$ & 0.06 & 0.00 & 0.83 & 0.80 \\
$\mathrm{hml}$ & 0.14 & 0.07 & 0.87 & 0.84 \\
$\mathrm{umd}$ & 0.05 & 0.00 & 0.86 & 0.82 \\
\hline
\end{tabular}

${ }^{a}$ The classical instruments are the explanatory variables lagged one period and the Chen-Roll-Ross ${ }^{35}$ factors. In addition to the classical instruments, the higher moment instruments include the higher moments of the regressors up to the fifth order.

which are supposed endogenous, to two groups of instruments: on one hand, the classical instruments comprising the lagged variables of the F\&F model and the Chen-Roll-Ross factors enumerated previously, and on the other hand instruments comprising, in addition to the classical instruments, the higher moments of the risk factors up to the fifth order.

As revealed by Table 3, the regressions of the $F \& F$ factors on the classical instruments are quite disappointing. The $R^{2}$ do not exceed 0.14 and the adjusted $R^{2}$ are very low. Moreover, regressing the risk factors on the higher moments gives quite good results. The lowest $R^{2}$, obtained by regressing $S M B$ on the higher moment instruments, is 0.80 . Using higher moments as instruments seems to be a great improvement over using only the classical ones.

Good instruments must also have a low correlation with the innovation term of the estimated model for which they are used to remove the eventual specification errors of that model. Table 4 shows the regression of the innovation term of the OLS estimation of the F\&F model performed on the HFR indices on
Table 4: Adjusted $R^{2}$ obtained by performing the regressions of the innovation of the OLS estimation of the F\&F model on the higher moment instruments for the period 1997-2005

\begin{tabular}{lc}
\hline HFR indices & $R^{2}$ adj. \\
\hline Distressed securities & 0.25 \\
Emerging & 0.18 \\
Equity hedge & 0.15 \\
Equity market neutral & 0.19 \\
Equity nonhedge & 0.25 \\
Event-driven & 0.14 \\
Fund of funds & 0.20 \\
Macro & 0.06 \\
Market timing & 0.19 \\
Short seller & 0.13 \\
Weighted composite & 0.07 \\
Average & 0.16 \\
\hline
\end{tabular}

the higher moment instruments. This adjusted $R^{2}$ of these regressions are quite low, the average $R^{2}$ being 0.16 . The maximum and minimum $R^{2}$ are respectively 0.25 for the distressed securities 
index and 0.06 for the macro one. Basically, these low $R^{2}$ are not a problem and the higher moments of the explanatory variables thus qualify as appropriate instruments.

\section{The estimated conditional version of the F\&F model for the HFR indices}

Tables 5 and 6 give respectively the OLS and the GMM-hm estimations of equation (10) for ten HFR indices. A comparison of the two tables reveals that the coefficients of these tables are different enough to suspect specification errors in the OLS estimation of our conditional version of the F\&F model. Coefficients are somewhat overstated and somewhat understated by the OLS estimation of a given strategy returns and the intensity of this problem seems in inverse relation with the $R^{2}$ of this strategy. ${ }^{42}$ Therefore, it seems preferable to resort to an IV method, like the GMM-hm method, to estimate the model. This procedure is unusual because the introduction of conditional variables in a financial model is generally viewed as a method per se to eliminate specification errors. But as a conditional model is actually an empirical model, it seems appropriate to estimate this model by an IV method in view of the differences between Tables 5 and 6 .

Table 6 reveals that the $R^{2}$ are quite high for the majority of the indices. Only the macro strategy has a $R^{2}$ below 0.5 . Two strategies, the distressed securities and the equity market neutral ones, have a $R^{2}$ comprised between 0.5 and 0.6 , while the other seven strategies have a $R^{2}$ higher than 0.6. But we know that the estimation of asset pricing models is always better for portfolios than for individual stocks and that may overstate the performance of these models. This is why we will repeat these estimations for the individual funds pooled by strategy in the next section.

Table 6 reveals that there seems to be a beta puzzle for only two strategies: the distressed securities and the short sellers one. For the short sellers strategy, the coefficient associated to the market risk premium in equation (9) is significant at the 10 per cent level, while it is not significant for the distressed one. Short sellers increase their beta when the risk premium decreases probably because the gains associated to short selling are more important during these periods because the stock market is then depressed. The hedge funds following the distressed securities strategy do the same thing because business opportunities are more important for them when the market risk premium is low. It is at this time that business failures surge. Therefore, the negative relation between the market risk premium and the beta observed for those two strategies is not really a puzzle but is associated to their style.

Always, according to Table 6, the relation between beta and the risk premium is positive for the other eight strategies, indicating the absence of a beta puzzle. In five cases, the beta is significant at the 5 per cent level. But it is difficult at the aggregation level of the indices to analyse dynamic strategies. Really, the portfolios constituted by the indices hide the heterogeneity of the funds composing these indices.

Table 6 also shows that the coefficient associated to the variable measuring market volatility in the equation of conditional beta (equation 9), that is $\left(R_{m t}-R_{f t}\right)^{2}$, is generally negative. In the majority of hedge fund strategies, the beta is reduced when market volatility increases, a rational behaviour. Two strategies, however, increase their beta when the market volatility increases: the equity market 
Table 5: OLS estimation of the conditional version of the Fama and French model, HFR indices, 1997-2005

\begin{tabular}{|c|c|c|c|c|c|c|c|c|c|c|}
\hline & $c$ & $m k t-r f$ & $s m b$ & $h m l$ & umd & alpha1 & beta1 & beta2 & $R^{2}$ & $D W$ \\
\hline \multirow[t]{2}{*}{ Distressed securities } & 0.2850 & 0.2233 & 0.1818 & 0.1071 & 0.0015 & -2.8297 & -0.0049 & -0.002886 & 0.61 & 1.63 \\
\hline & 2.06 & 7.13 & 5.83 & 2.68 & 0.07 & 3.59 & 0.90 & 3.98 & & \\
\hline \multirow[t]{2}{*}{ Emerging } & 0.0729 & 0.7365 & 0.3298 & 0.1463 & 0.0611 & -4.2278 & 0.0056 & -0.0042 & 0.64 & 1.58 \\
\hline & 0.21 & 9.50 & 4.28 & 1.48 & 1.17 & 2.17 & 0.42 & 2.32 & & \\
\hline \multirow[t]{2}{*}{ Equity hedge } & 0.5627 & 0.5037 & 0.2592 & -0.0014 & 0.0750 & 2.1480 & 0.0083 & -0.0001 & 0.87 & 1.52 \\
\hline & 4.39 & 17.21 & 8.91 & 0.04 & 3.82 & 2.92 & 1.65 & 0.08 & & \\
\hline \multirow[t]{2}{*}{ Equity market neutral } & 0.1874 & 0.1157 & 0.0445 & 0.1114 & 0.1344 & 0.9350 & 0.0034 & 0.0003 & 0.56 & 1.86 \\
\hline & 2.14 & 5.77 & 2.23 & 4.36 & 9.99 & 1.86 & 0.98 & 0.72 & & \\
\hline \multirow[t]{2}{*}{ Equity non hedge } & 0.3633 & 0.7768 & 0.4198 & -0.0093 & 0.0184 & 1.0436 & 0.0077 & -0.0004 & 0.94 & 1.88 \\
\hline & 2.63 & 24.63 & 13.39 & 0.23 & 0.87 & 1.32 & 1.41 & 0.48 & & \\
\hline \multirow[t]{2}{*}{ Event driven } & 0.4153 & 0.3894 & 0.2281 & 0.1592 & -0.0082 & 0.1408 & -0.0016 & -0.0018 & 0.83 & 1.80 \\
\hline & 3.92 & 16.08 & 9.47 & 5.16 & 0.50 & 0.23 & 0.39 & 3.20 & & \\
\hline Fund of funds & 0.2399 & 0.2293 & 0.1397 & 0.0628 & 0.0564 & 0.3418 & 0.0042 & -0.0014 & 0.72 & 1.59 \\
\hline \multirow[t]{2}{*}{ Macro } & 0.0046 & 0.2343 & 0.1706 & 0.1688 & 0.0684 & -1.7352 & 0.0211 & 0.0011 & 0.35 & 1.89 \\
\hline & 0.02 & 5.27 & 3.86 & 2.98 & 2.29 & 1.56 & 2.76 & 1.10 & & \\
\hline \multirow[t]{2}{*}{ Market timing } & 0.5573 & 0.3855 & 0.0724 & -0.0141 & 0.0636 & 1.4921 & 0.0232 & 0.0000 & 0.68 & 2.28 \\
\hline & 3.64 & 11.01 & 2.08 & 0.32 & 2.71 & 1.70 & 3.85 & 0.04 & & \\
\hline \multirow[t]{2}{*}{ Short seller } & 0.6278 & -1.0067 & -0.4296 & 0.3842 & -0.1422 & -0.4189 & -0.0170 & -0.0016 & 0.87 & 2.36 \\
\hline & 2.06 & 14.46 & 6.21 & 4.33 & 3.04 & 0.24 & 1.42 & 0.99 & & \\
\hline Mean level of the coef. & 0.3316 & 0.2588 & 0.1416 & 0.1115 & 0.0329 & -0.3110 & 0.0050 & -0.0011 & 0.71 & 1.84 \\
\hline Mean level of the $t$-stat. & 2.37 & 12.20 & 6.30 & 2.39 & 2.85 & 1.62 & 1.49 & 1.58 & & \\
\hline \multirow[t]{2}{*}{ Weighted composite } & 0.4321 & 0.3952 & 0.1959 & 0.0212 & 0.0392 & 0.7677 & 0.0032 & -0.0009 & 0.87 & 1.44 \\
\hline & 4.49 & 17.98 & 8.96 & 0.76 & 2.66 & 1.39 & 0.83 & 1.77 & & \\
\hline
\end{tabular}

${ }^{a}$ The conditional version of the F\&F model is given by equation (10). The variable alpha1 is the three-month T-bills rate lagged one period, expressed in deviation from its mean. The variable beta1 is the product of the market risk premium, on the one hand, and the market risk premium lagged one period and expressed in deviation from its mean, on the other hand. If the coefficient of this variable is negative, there is an apparent beta puzzle. The variable beta 2 is the product of the market risk premium, on the one hand, and the squared market risk premium lagged one period and expressed in deviation from its mean, on the other hand. The last variable wants to verify the impact of market volatility on beta. The $t$-statistics are expressed in absolute value. 


\begin{tabular}{|c|c|c|c|c|c|c|c|c|c|c|}
\hline & $c$ & $m k t-1 f$ & $s m b$ & $h m l$ & umd & alpha1 & beta 1 & beta 2 & $R^{2}$ & $D W$ \\
\hline \multirow[t]{2}{*}{ Distressed securities } & 0.1110 & 0.2431 & 0.1868 & 0.1210 & 0.0157 & -5.0376 & -0.0018 & -0.0027 & 0.56 & 1.53 \\
\hline & 1.10 & 11.78 & 8.11 & 4.00 & 0.95 & 6.87 & 0.62 & 6.34 & & \\
\hline \multirow[t]{2}{*}{ Emerging } & 0.2838 & 0.6425 & 0.2755 & 0.0230 & 0.0477 & -3.2867 & 0.0071 & -0.0042 & 0.61 & 1.59 \\
\hline & 0.99 & 11.52 & 6.05 & 0.37 & 1.26 & 1.91 & 0.74 & 3.88 & & \\
\hline \multirow[t]{2}{*}{ Equity hedge } & 0.6406 & 0.4698 & 0.2551 & -0.0328 & 0.0607 & 3.3337 & 0.0083 & -0.0001 & 0.86 & 1.53 \\
\hline & 6.28 & 28.26 & 14.41 & 1.64 & 6.72 & 4.26 & 3.36 & 0.31 & & \\
\hline \multirow[t]{2}{*}{ Equity market neutral } & 0.1951 & 0.1184 & 0.0482 & 0.1265 & 0.1330 & 1.3365 & 0.0039 & 0.0004 & 0.52 & 1.88 \\
\hline & 2.29 & 5.71 & 3.43 & 5.25 & 12.47 & 2.23 & 1.99 & 2.20 & & \\
\hline \multirow[t]{2}{*}{ Equity non hedge } & 0.4334 & 0.7655 & 0.4247 & -0.0251 & 0.0087 & 1.8087 & 0.0076 & -0.0004 & 0.93 & 1.89 \\
\hline & 3.21 & 26.57 & 19.32 & 0.98 & 0.43 & 1.72 & 2.42 & 1.42 & & \\
\hline \multirow{2}{*}{ Event driven } & 0.3397 & 0.3909 & 0.2250 & 0.1659 & 0.0017 & -0.3633 & 0.0002 & -0.0015 & 0.81 & 1.76 \\
\hline & 5.00 & 16.94 & 15.33 & 7.19 & 0.18 & 0.78 & 0.08 & 4.84 & & \\
\hline \multirow[t]{2}{*}{ Fund of funds } & 0.2922 & 0.2122 & 0.1411 & 0.0479 & 0.0490 & 0.2558 & 0.0042 & -0.0014 & 0.70 & 1.60 \\
\hline & 4.02 & 9.87 & 11.02 & 2.79 & 5.60 & 0.40 & 1.54 & 4.84 & & \\
\hline \multirow[t]{2}{*}{ Macro } & -0.1843 & 0.2595 & 0.1640 & 0.1860 & 0.0967 & -4.8921 & 0.0211 & 0.0012 & 0.25 & 1.77 \\
\hline & 1.23 & 8.31 & 5.46 & 4.01 & 4.34 & 4.45 & 3.63 & 1.97 & & \\
\hline \multirow[t]{2}{*}{ Market timing } & 0.5217 & 0.3638 & 0.0790 & -0.0114 & 0.0583 & 1.0175 & 0.0222 & -0.0002 & 0.66 & 2.27 \\
\hline & 4.24 & 12.35 & 4.37 & 0.34 & 3.19 & 1.00 & 5.01 & 0.56 & & \\
\hline \multirow[t]{2}{*}{ Short seller } & 1.0468 & -1.0059 & -0.4252 & 0.3987 & -0.1780 & 1.7115 & -0.0173 & -0.0016 & 0.85 & 2.34 \\
\hline & 5.59 & 16.66 & 8.21 & 5.92 & 10.11 & 0.89 & 1.66 & 1.58 & & \\
\hline Mean level of the coef. & 0.3680 & 0.2460 & 0.1374 & 0.1000 & 0.0294 & -0.4116 & 0.0056 & -0.0010 & 0.68 & 1.82 \\
\hline Mean level of the $t$-stat. & 3.40 & 14.80 & 9.57 & 3.25 & 4.53 & 2.45 & 2.11 & 2.79 & & \\
\hline \multirow[t]{2}{*}{ Weighted composite } & 0.4792 & 0.3925 & 0.1870 & 0.0035 & 0.0374 & 1.2839 & 0.0033 & -0.0009 & 0.87 & 1.47 \\
\hline & 5.61 & 24.27 & 12.97 & 0.18 & 6.10 & 2.16 & 1.41 & 3.01 & & \\
\hline
\end{tabular}

${ }^{a}$ The GMM-hm estimation uses as instruments the higher moments of the risk factors up to the fifth order, as explained in the second section. The conditional version of the F\&F model is given by equation (10). The variable alpha1 is the three-month T-bills rate lagged one period, expressed in deviation from its mean. The variable beta1 is the product of the market risk premium, on the one hand, and the market risk premium lagged one period and expressed in deviation from its mean, on the other hand. If the coefficient of this variable is negative, there is an apparent beta puzzle. The variable beta 2 is the product of the market risk premium, on the one hand, and the squared market risk premium lagged one period and expressed in deviation from its mean, on the other hand. The last variable wants to verify the impact of market volatility on beta. The $t$-statistics are expressed in absolute value. 
neutral and the macro strategies. Before interpreting these results, we will wait for a confirmation of those results at the level of individual funds.

\section{The estimated conditional version of the F\&F model for the individual funds pooled by strategies}

Table 7 gives GMM-hm estimations of the individual funds grouped by strategies. These estimations were not performed in panel but were done separately on each individual fund and the results were then averaged by strategy. Usually, the researchers resort to this method of estimation. By comparing it to Table 9 where estimations are done in panel, we notice that the panel results are generally much superior in terms of the $R^{2}$ and the $t$-statistics of the estimated coefficients. Therefore, we will only discuss the results for the panel estimations.

For the panel estimations of hedge funds pooled by strategies, we resort to cross-section SUR, ${ }^{43}$ to allow for the interactions between the funds within a strategy, and to fixed effects, to account for the heterogeneity of the funds within the same strategy. This procedure generally greatly improves our results over those obtained by a simple averaging of the results within a strategy, as shown by a comparison of Table 7 , on the one hand, and Tables 8 and 9, on the other hand. Furthermore, we will only discuss here the GMM-hm estimation in panel because, as shown previously, the OLS estimation is plagued by specification errors.

Table 9 gives the GMM-hm estimation in panel of the individual funds returns pooled by strategy. The conditional model performs quite well for the three most important strategies of the hedge fund industry, which are the fund of funds, the equity hedge and equity nonhedge strategies. ${ }^{44}$ The $R^{2}$ of the regressions for these strategies are respectively $0.94,0.88$ and 0.61 . The estimated panel is also satisfying for the short seller strategy, whose $R^{2}$ is 0.60 . Besides, the estimations are poor for four very specialised strategies whose $R^{2}$ is below 0.25 : the distressed securities, equity market neutral, macro and managed futures strategies. The conditional model is particularly deceiving for the macro strategy whose $R^{2}$ is only 0.04 . As said previously, the estimation of the indices, by aggregating the funds of the same strategy, may give way to a result that is not supported by the panel estimation of those same strategies. For instance, the $R^{2}$ decreases sensibly when shifting from the indices to the individual funds for five strategies: the distressed securities, emerging, equity market neutral, event-driven and market timing. The decrease of the $R^{2}$ of the eventdriven strategy, from 0.81 to 0.34 , is especially important. Notice that the strategies whose panel estimation is deceiving are not the most important ones but, as said before, are very specialised strategies. The F\&F model does not seem to be appropriate for those strategies.

The apparent beta puzzle, which was observed for the distressed securities and the short sellers strategies when estimating the indices, is corroborated by the panel estimation. For those strategies, the coefficient of the risk premium is negative and significant at the 5 per cent level. As explained previously, there is not really a beta puzzle for these two strategies because the negative link between the beta and the risk premium is the expression of a rational behaviour. Moreover, for two other strategies, the emerging market and the event-driven ones, the coefficient of the risk premium is negative in their beta equation but not significant neither at 


\begin{tabular}{|c|c|c|c|c|c|c|c|c|c|c|}
\hline \multicolumn{11}{|c|}{$\begin{array}{l}\text { Table 7: GMM-hm estimation of the conditional version of the Fama and French model, individual HFR funds grouped by } \\
\text { strategies, averages of the unpooled results, } 1997-2005^{a}\end{array}$} \\
\hline & $c$ & $m k t-r f$ & $s m b$ & $h m l$ & umd & alpha1 & beta1 & beta2 & $R^{2}$ & $D W$ \\
\hline \multirow{6}{*}{$\begin{array}{l}\text { Distressed securities } \\
t \text {-stat } \\
\text { s.d. } \\
\text { Emerging }\end{array}$} & 0.2030 & 0.1767 & 0.1181 & 0.1166 & 0.0070 & -4.1868 & -0.0024 & -0.0021 & 0.24 & 1.70 \\
\hline & 1.97 & 5.24 & 5.20 & 4.77 & 2.24 & 3.70 & 1.53 & 4.13 & & \\
\hline & 0.2281 & 0.0889 & 0.0908 & 0.1976 & 0.0362 & 1.9707 & 0.0094 & 0.0014 & & \\
\hline & 0.6163 & 0.7453 & 0.1939 & 0.0495 & 0.0055 & -1.6185 & -0.0079 & -0.0070 & 0.28 & 1.73 \\
\hline & 2.01 & 6.31 & 2.66 & 1.55 & 2.53 & 1.18 & 1.19 & 2.79 & & \\
\hline & 1.2759 & 0.4529 & 0.1887 & 0.2527 & 0.1265 & 6.3492 & 0.0304 & 0.0079 & & \\
\hline \multirow[t]{3}{*}{ Equity hedge } & 0.5589 & 0.5142 & 0.2982 & 0.1180 & 0.0774 & 2.5736 & 0.0137 & -0.0002 & 0.45 & 1.84 \\
\hline & 2.51 & 8.74 & 5.81 & 3.11 & 4.71 & 2.01 & 2.04 & 1.56 & & \\
\hline & 0.5657 & 0.3231 & 0.2386 & 0.3110 & 0.1946 & 5.2771 & 0.0226 & 0.0026 & & \\
\hline \multirow[t]{3}{*}{ Equity market neutral } & 0.1396 & 0.1819 & -0.0310 & 0.0668 & 0.0890 & 0.7669 & 0.0020 & -0.0001 & 0.26 & 1.83 \\
\hline & 2.53 & 4.81 & 3.07 & 2.57 & 5.07 & 1.61 & 1.50 & 1.72 & & \\
\hline & 0.4137 & 0.3567 & 0.1414 & 0.1623 & 0.1361 & 2.7306 & 0.0126 & 0.0011 & & \\
\hline \multirow[t]{3}{*}{ Equity non hedge } & 0.3070 & 0.7964 & 0.2971 & 0.2369 & -0.0162 & -0.3823 & 0.0044 & -0.0001 & 0.55 & 1.92 \\
\hline & 1.64 & 13.24 & 5.24 & 4.55 & 3.94 & 1.76 & 1.85 & 1.53 & & \\
\hline & 0.6682 & 0.2838 & 0.2856 & 0.4266 & 0.1709 & 6.2911 & 0.0360 & 0.0046 & & \\
\hline \multirow[t]{3}{*}{ Event driven } & 0.2250 & 0.3530 & 0.2359 & 0.1631 & -0.0324 & -1.3193 & -0.0030 & -0.0017 & 0.39 & 1.75 \\
\hline & 2.82 & 8.08 & 6.44 & 4.64 & 1.94 & 1.62 & 1.94 & 2.84 & & \\
\hline & 0.5754 & 0.2588 & 0.2490 & 0.1771 & 0.1276 & 3.7938 & 0.0113 & 0.0022 & & \\
\hline \multirow[t]{3}{*}{ Fund of funds } & 0.3726 & 0.2200 & 0.1348 & 0.0514 & 0.0523 & 0.6538 & 0.0069 & -0.0013 & 0.38 & 1.74 \\
\hline & 4.18 & 7.41 & 5.94 & 2.59 & 4.91 & 2.02 & 2.05 & 2.97 & & \\
\hline & 0.3826 & 0.1553 & 0.0803 & 0.0880 & 0.0746 & 3.0009 & 0.0114 & 0.0024 & & \\
\hline
\end{tabular}


Table 7: Continued

\begin{tabular}{|c|c|c|c|c|c|c|c|c|c|c|}
\hline & $c$ & $m k t-r f$ & smb & $h m l$ & umd & alpha1 & beta1 & beta2 & $R^{2}$ & $D W$ \\
\hline \multirow[t]{3}{*}{ Macro } & 0.2021 & 0.0941 & 0.0828 & 0.0840 & 0.0790 & -0.2836 & 0.0288 & 0.0026 & 0.10 & 1.97 \\
\hline & 2.15 & 2.94 & 1.75 & 1.49 & 2.66 & 1.80 & 2.95 & 3.03 & & \\
\hline & 0.6555 & 0.2100 & 0.1236 & 0.1346 & 0.0801 & 6.2601 & 0.0209 & 0.0038 & & \\
\hline \multirow[t]{3}{*}{ Managed futures } & 0.3818 & -0.0895 & 0.0576 & 0.0691 & 0.1045 & 1.4632 & 0.0429 & 0.0029 & 0.06 & 1.97 \\
\hline & 1.97 & 2.00 & 1.61 & 1.27 & 3.07 & 1.32 & 3.06 & 2.11 & & \\
\hline & 0.6165 & 0.2208 & 0.1400 & 0.1583 & 0.1165 & 5.3304 & 0.0411 & 0.0053 & & \\
\hline \multirow[t]{3}{*}{ Market timing } & 0.3511 & 0.4542 & 0.1829 & 0.0133 & 0.1427 & 1.3770 & 0.0371 & 0.0010 & 0.41 & 2.11 \\
\hline & 3.40 & 9.30 & 3.78 & 2.21 & 4.83 & 2.00 & 4.98 & 1.43 & & \\
\hline & 0.6154 & 0.2544 & 0.2388 & 0.1298 & 0.0526 & 3.7178 & 0.0194 & 0.0008 & & \\
\hline \multirow[t]{3}{*}{ Short seller } & 0.9401 & -1.2054 & -0.4105 & 0.3995 & -0.1325 & 4.5819 & -0.0137 & 0.0012 & 0.76 & 1.89 \\
\hline & 2.89 & 17.16 & 5.53 & 4.25 & 6.58 & 1.59 & 2.90 & 1.07 & & \\
\hline & 0.9979 & 0.1442 & 0.3367 & 0.1772 & 0.2407 & 4.6083 & 0.0466 & 0.0018 & & \\
\hline Mean level coef. & 0.3907 & 0.2037 & 0.1054 & 0.1244 & 0.0342 & 0.3296 & 0.0099 & -0.0004 & 0.3530 & 1.86 \\
\hline Mean level $t$-stat & 2.55 & 7.75 & 4.28 & 3.00 & 3.86 & 1.87 & 2.36 & 2.29 & & \\
\hline Mean level s.d. & 0.6359 & 0.2499 & 0.1921 & 0.2014 & 0.1233 & 4.4846 & 0.0238 & 0.0031 & & \\
\hline
\end{tabular}

${ }^{a}$ For each strategy, equation (10) is estimated separately for each individual fund and the results are averaged. The GMM-hm estimation uses as instruments the higher moments of the risk factors up to the fifth order, as explained in the second section. The variable alpha1 is the three-month Tbills rate lagged one period, expressed in deviation from its mean. The variable beta1 is the product of the market risk premium, on the one hand, and the market risk premium lagged one period and expressed in deviation from its mean, on the other hand. If the coefficient of this variable is negative, there is an apparent beta puzzle. The variable beta 2 is the product of the market risk premium, on the one hand, and the squared market risk premium lagged one period and expressed in deviation from its mean, on the other hand. The last variable wants to verify the impact of market volatility on beta. The $t$-statistics are expressed in absolute value. 
Table 8: OLS estimation of the conditional model in panel for the HFR funds pooled by strategies $^{a}$

\begin{tabular}{|c|c|c|c|c|c|c|c|c|c|c|}
\hline & $c$ & $m k t-r f$ & $s m b$ & $h m l$ & umd & alpha1 & beta1 & beta2 & $R^{2}$ & $D W$ \\
\hline \multirow[t]{2}{*}{ Distressed securities } & 0.4468 & 0.1178 & 0.1102 & 0.1111 & -0.0214 & -2.0724 & -0.0030 & -0.0019 & 0.25 & 1.72 \\
\hline & 13.29 & 15.46 & 14.52 & 11.43 & 4.20 & 10.79 & 2.29 & 10.79 & & \\
\hline \multirow[t]{2}{*}{ Emerging } & 0.3398 & 0.7533 & 0.3144 & 0.2188 & -0.0126 & -2.8652 & 0.0044 & -0.0046 & 0.16 & 2.00 \\
\hline & 1.97 & 19.23 & 8.05 & 4.38 & 0.48 & 2.90 & 0.65 & 5.11 & & \\
\hline \multirow[t]{2}{*}{ Equity hedge } & 0.4833 & 0.5418 & 0.3013 & 0.1374 & 0.0814 & 1.7578 & 0.0143 & -0.0001 & 0.87 & 2.02 \\
\hline & 39.88 & 197.26 & 110.07 & 39.19 & 44.20 & 25.38 & 30.25 & 1.38 & & \\
\hline \multirow[t]{2}{*}{ Equity market neutral } & 0.1474 & 0.1487 & -0.0254 & 0.0295 & 0.0613 & -0.2231 & 0.0001 & -0.0003 & 0.14 & 1.95 \\
\hline & 3.40 & 15.12 & 2.59 & 2.35 & 9.31 & 0.90 & 0.09 & 1.51 & & \\
\hline \multirow[t]{2}{*}{ Equity non hedge } & 0.4786 & 0.7777 & 0.2902 & 0.2090 & -0.0202 & 0.7408 & 0.0058 & 0.0000 & 0.69 & 2.02 \\
\hline & 11.44 & 82.04 & 30.72 & 17.28 & 3.18 & 3.10 & 3.54 & 0.19 & & \\
\hline \multirow[t]{2}{*}{ Event driven } & 0.4214 & 0.2539 & 0.1544 & 0.1399 & -0.0169 & 0.0078 & -0.0035 & -0.0018 & 0.34 & 1.75 \\
\hline & 13.87 & 36.87 & 22.51 & 15.93 & 3.65 & 0.04 & 2.97 & 11.30 & & \\
\hline \multirow[t]{2}{*}{ Fund of funds } & 0.3099 & 0.2320 & 0.1358 & 0.0696 & 0.0556 & 0.2834 & 0.0062 & -0.0013 & 0.94 & 2.01 \\
\hline & 25.06 & 82.72 & 48.63 & 19.46 & 29.59 & 4.01 & 12.90 & 19.33 & & \\
\hline \multirow[t]{2}{*}{ Macro } & 0.3449 & 0.1190 & 0.0534 & 0.0984 & 0.0565 & 0.1889 & 0.0202 & 0.0024 & 0.06 & 1.98 \\
\hline & 5.79 & 8.74 & 3.94 & 5.67 & 6.18 & 0.55 & 8.62 & 7.65 & & \\
\hline \multirow[t]{2}{*}{ Managed futures } & 0.2222 & -0.0296 & 0.0858 & 0.1405 & 0.0995 & -0.5586 & 0.0414 & 0.0033 & 0.15 & 2.01 \\
\hline & 3.77 & 2.22 & 6.45 & 8.25 & 11.12 & 1.66 & 18.02 & 10.75 & & \\
\hline \multirow[t]{2}{*}{ Market timing } & 0.4073 & 0.3737 & 0.1083 & 0.0092 & 0.1164 & 0.9062 & 0.0274 & 0.0008 & 0.33 & 2.08 \\
\hline & 3.90 & 15.77 & 4.59 & 0.30 & 7.33 & 1.52 & 6.73 & 1.53 & & \\
\hline \multirow[t]{2}{*}{ Short seller } & 0.5707 & -1.1680 & -0.4186 & 0.3380 & -0.0578 & 1.4104 & -0.0148 & 0.0010 & 0.65 & 1.93 \\
\hline & 2.00 & 19.49 & 4.94 & 5.40 & 1.74 & 1.14 & 1.49 & 1.06 & & \\
\hline Mean level of coef. & 0.3793 & 0.1928 & 0.1009 & 0.1365 & 0.0311 & -0.0385 & 0.0090 & -0.0002 & 0.42 & 1.95 \\
\hline Mean level of $t$-stat & 11.31 & 44.99 & 23.36 & 11.79 & 11.00 & 4.73 & 7.96 & 6.42 & & \\
\hline
\end{tabular}

${ }^{a}$ The conditional version of the Fama and French model is given by equation (10). For each strategy, the excess returns of the individual funds are estimated in panel. This method uses fixed effects to account for heterogeneity of the funds in a given strategy and cross-section SUR (seemingly unrelated regression) to take into account the interaction of the funds within a strategy. The variable alpha1 is the three-month T-bills rate lagged one period, expressed in deviation from its mean. The variable beta1 is the product of the market risk premium, on the one hand, and the market risk premium lagged one period and expressed in deviation from its mean, on the other hand. If the coefficient of this variable is negative, there is an apparent beta puzzle. The variable beta 2 is the product of the market risk premium, on the one hand, and the squared market risk premium lagged one period and expressed in deviation from its mean, on the other hand. The last variable wants to verify the impact of market volatility on beta. The $t$-statistics are expressed in absolute value.

the 5 per cent nor at the 10 per cent level. Finally, for five strategies, the coefficient associated to the risk premium in the beta equation is positive and significant at the 5 per cent level, indicating the absence of a beta puzzle. These strategies are: equity hedge, equity 
Table 9: GMM-hm estimation of the conditional model in panel for the HFR funds pooled by strategies $^{a}$

\begin{tabular}{|c|c|c|c|c|c|c|c|c|c|c|}
\hline & $c$ & $m k t-r f$ & $s m b$ & $h m l$ & umd & alpha1 & beta1 & beta2 & $R^{2}$ & $D W$ \\
\hline \multirow[t]{2}{*}{ Distressed securities } & 0.3068 & 0.1349 & 0.1259 & 0.1431 & -0.0220 & -3.7814 & -0.0073 & -0.0023 & 0.22 & 1.70 \\
\hline & 6.60 & 12.18 & 13.44 & 10.90 & 3.36 & 9.67 & 2.37 & 7.69 & & \\
\hline \multirow[t]{2}{*}{ Emerging } & 0.5966 & 0.6874 & 0.2305 & 0.0592 & -0.0396 & -2.8503 & -0.0144 & -0.0090 & 0.15 & 2.00 \\
\hline & 2.91 & 11.47 & 4.59 & 0.86 & 1.12 & 2.53 & 0.87 & 5.65 & & \\
\hline \multirow[t]{2}{*}{ Equity hedge } & 0.5235 & 0.5640 & 0.2939 & 0.1250 & 0.0956 & 2.8235 & 0.0325 & 0.0001 & 0.88 & 2.01 \\
\hline & 31.40 & 141.81 & 87.38 & 26.51 & 40.75 & 20.11 & 29.30 & 1.25 & & \\
\hline \multirow[t]{2}{*}{ Equity market neutral } & 0.2344 & 0.1601 & -0.0325 & 0.0289 & 0.0594 & 1.1529 & 0.0081 & -0.0002 & 0.11 & 1.94 \\
\hline & 3.62 & 10.33 & 2.48 & 1.58 & 6.51 & 2.11 & 1.89 & 0.43 & & \\
\hline \multirow[t]{2}{*}{ Equity non hedge } & 0.4307 & 0.8191 & 0.2808 & 0.2410 & -0.0067 & 0.9266 & 0.0221 & 0.0000 & 0.61 & 2.02 \\
\hline & 6.66 & 53.12 & 21.53 & 13.18 & 0.74 & 1.70 & 5.13 & 0.01 & & \\
\hline \multirow[t]{2}{*}{ Event driven } & 0.3362 & 0.2705 & 0.1678 & 0.1645 & -0.0084 & -0.7289 & -0.0004 & -0.0020 & 0.34 & 1.76 \\
\hline & 8.81 & 29.71 & 21.80 & 15.24 & 1.57 & 2.27 & 0.15 & 8.03 & & \\
\hline \multirow[t]{2}{*}{ Fund of funds } & 0.3332 & 0.2360 & 0.1342 & 0.0528 & 0.0555 & 0.6207 & 0.0131 & -0.0012 & 0.94 & 2.01 \\
\hline & 19.84 & 58.78 & 39.62 & 11.12 & 23.50 & 4.39 & 11.72 & 10.74 & & \\
\hline \multirow[t]{2}{*}{ Macro } & 0.3502 & 0.0770 & 0.0526 & 0.0694 & 0.0406 & -0.5854 & 0.0097 & 0.0024 & 0.04 & 1.98 \\
\hline & 4.60 & 4.18 & 3.39 & 3.18 & 3.74 & 0.90 & 1.88 & 4.86 & & \\
\hline \multirow[t]{2}{*}{ Managed futures } & 0.2008 & -0.0650 & 0.0403 & 0.0747 & 0.1138 & -0.6383 & 0.0554 & 0.0066 & 0.14 & 2.02 \\
\hline & 2.03 & 2.75 & 2.01 & 2.66 & 8.16 & 0.76 & 8.39 & 10.33 & & \\
\hline \multirow[t]{2}{*}{ Market timing } & 0.3442 & 0.4119 & 0.1056 & -0.0060 & 0.1452 & 1.0843 & 0.0572 & 0.0015 & 0.30 & 2.07 \\
\hline & 2.36 & 11.85 & 3.59 & -0.15 & 7.09 & 0.88 & 5.90 & 1.63 & & \\
\hline \multirow[t]{2}{*}{ Short seller } & 0.7784 & -1.2509 & -0.4328 & 0.2778 & -0.1468 & 0.8281 & -0.0560 & -0.0023 & 0.60 & 1.92 \\
\hline & 2.81 & 13.64 & 4.26 & 3.42 & 3.45 & 0.57 & 3.01 & 1.41 & & \\
\hline Mean level of coef. & 0.4032 & 0.1859 & 0.0878 & 0.1119 & 0.0261 & -0.1044 & 0.0109 & -0.0006 & 0.39 & 1.95 \\
\hline Mean level of $t$-stat & 8.33 & 31.80 & 18.55 & 8.05 & 9.09 & 4.17 & 6.42 & 4.73 & & \\
\hline
\end{tabular}

${ }^{a}$ The conditional version of the Fama and French model is given by equation (10). For each strategy, the excess returns of the individual funds are estimated in panel. This method uses fixed effects to account for heterogeneity of the funds in a given strategy and cross-section SUR (seemingly unrelated regression) to take into account the interaction of the funds within a strategy. Moreover, the GMM-hm estimation uses as instruments the higher moments of the risk factors up to the fifth order, as explained in the second section. The variable alpha1 is the three-month T-bills rate lagged one period, expressed in deviation from its mean. The variable beta1 is the product of the market risk premium, on the one hand, and the market risk premium lagged one period and expressed in deviation from its mean, on the other hand. If the coefficient of this variable is negative, there is an apparent beta puzzle. The variable beta2 is the product of the market risk premium, on the one hand, and the squared market risk premium lagged one period and expressed in deviation from its mean, on the other hand. The last variable wants to verify the impact of market volatility on beta. The $t$-statistics are expressed in absolute value. 
nonhedge, fund of funds, managed futures and market timing. For the macro strategy, the coefficient is positive and significant at the 10 per cent level.

Table 9 reveals that hedge funds usually reduce their beta when market volatility increases. For two strategies, the macro and managed futures ones, an increase in market volatility leads them to increase their beta. That relationship may be linked to their market timing activities but it may also reflect that volatility per se is a positive factor for these strategies. The volatility of macroeconomic variables is related to market volatility and macro funds have more business

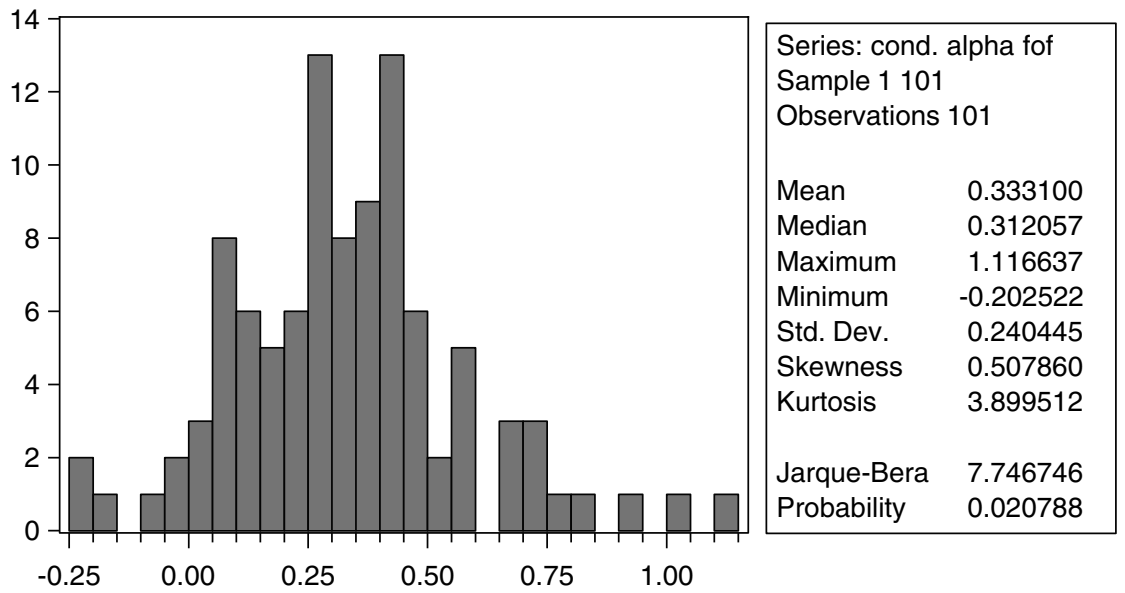

Figure 1: Distribution of the fixed effects in the panel GMM-hm estimation of the funds of funds strategy conditional model

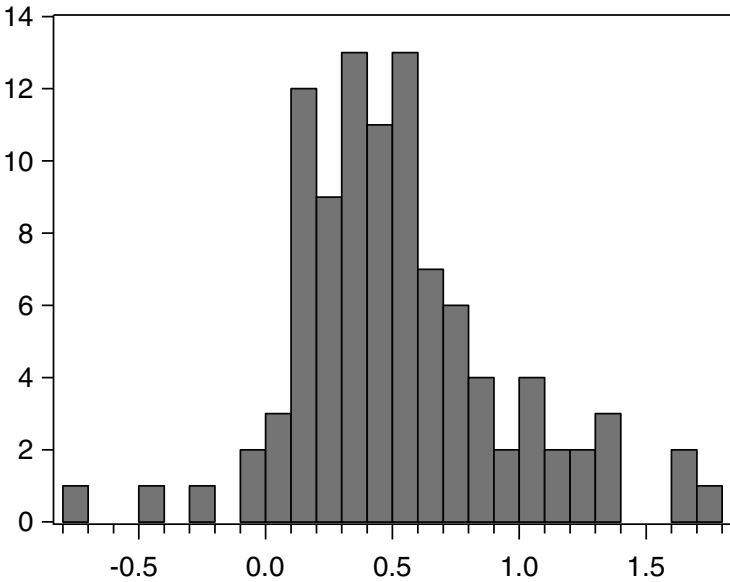

Series: cond. alpha equity hedge Sample 199

Observations 99

Mean

0.523500

Median

0.468228

Maximum $\quad 1.713555$

Minimum $\quad-0.794670$

Std. Dev. $\quad 0.422597$

Skewness $\quad 0.442032$

Kurtosis $\quad 4.131417$

Jarque-Bera $\quad 8.504402$

Probability $\quad 0.014233$

Figure 2: Distribution of the fixed effects in the panel GMM-hm estimation of the equity hedge strategy conditional model 
opportunities when the macroeconomic variables are more volatile. For managed futures, market volatility generally increases their profit opportunities. The coefficient of the squared market premium is also positive for the market timing strategy but it is significant only at the 10 per cent level. That might indicate in this case good market timing by the funds following this strategy.

Finally, Figures 1 and 2 show the fixed effects distribution for the two most important groups of hedge funds in our sample, which are the equity hedge and the fund of funds. At Figure 1, we see that the average alpha for the fund of funds group is relatively moderate at 0.33 per cent but also that the standard deviation is quite high at 0.24 . Therefore, the fund of funds group is very heterogeneous, the test for the fixed effects being incidentally very significant. Furthermore, a proportion of 6 per cent of these funds had an alpha under 0 over the period of analysis. We could make the same observations for the equity hedge group (Figure 1), except that the average alpha, at 0.52 , is higher for this group. These results serve to qualify the high levels of estimated alphas in the case of the indices that might lead to suspect market inefficiencies.

\section{CONCLUSION}

Our contribution in this paper was threefold. First, we showed that it is preferable to estimate conditional models using an IV method because our empirical works suggest that there are many specification errors in the OLS estimation of such models, which are by nature empirical and may thus be contaminated by such errors. To do so, we proposed a new set of instruments based on the higher moments of the F\&F model.
These instruments were viewed as very promising to estimate asset pricing models. These estimation procedures generally greatly improve the fit of the estimations.

Secondly, we made our GMM-hm estimations in panel to estimate our conditional version of the F\&F model. We showed that this procedure is much better than the simple averaging of results by strategy. It allows introducing fixed effects to account for the heterogeneity of the funds forming a strategy and cross-section SUR to take into account the interactions of the funds within a strategy.

Finally, we showed, with the help of a conditional version of the F\&F model, that there does not seem to be a beta puzzle in the hedge fund industry. There is, however, an apparent beta puzzle for very specialised strategies, like the distressed securities and the short sellers one. But for those strategies, the negative link between their beta and the market risk premium is not really a puzzle because business opportunities are greater for the funds comprising these strategies when the stock market is depressed.

\section{References and Notes}

1 Ferson, W.E. and Schadt, R.W. (1996) 'Measuring Fund Strategy and Performance in Changing Economic Conditions', Journal of Finance, Vol. 51, pp. 425-461.

2 Watson, C.T. (2003) 'GMM and the Fama and French Model: The Role of Instruments', Economics Department (UCLA), Working paper.

3 SUR is the acronym of: Seemingly unrelated regressions.

4 This section is based on our previous works: Coën et al. ${ }^{5,6}$ and Racicot and Théoret. ${ }^{7}$

5 Coën, A., Racicot, F.E. and Théoret, R. (2006a) 'Hedge Funds Returns, Higher Moments and Nonlinear Risk', in Gregoriou, G. N., Kaiser, D. (eds.), 'Hedge Funds and Managed Futures: a Handbook for Institutional Investors', Risk Books, London.

6 Coën, A., Racicot, F.E. and Théoret, R. (2006b) 'Higher Moments as Risk Instruments to Discard Errors in Variables: The Case of the Fama and French 
Model', Proceedings of the Global Finance Association. Rio de Janeiro.

7 Racicot, F.E. and Théoret, R. (2006) 'On Comparing Hedge Fund Strategies Using Higher Moment Estimators for Correcting Specification Errors in Financial Models', in Gregoriou, G. N., Kaiser, D. (eds.), 'Hedge Funds and Managed Futures: a Handbook for Institutional Investors', Risk Books, London.

8 Fama, E.F. and French, K.R. (1992) 'The CrossSection of Expected Stock Returns', Journal of Finance, Vol. 47, No. 2, pp. 427-465.

9 Fama, E.F. and French, K.R. (1993) 'Common Risk Factors in the Returns on Stocks and Bonds', Journal of Financial Economics, Vol. 33, pp. 3-56.

10 Fama, E.F. and French, K.R. (1997) 'Industry Costs of Equity', Journal of Financial Economics, Vol. 43, pp. 153-193.

11 The original F\&F model contained only the first two 'anomalies'. The momentum anomaly, which is due to Carhart ${ }^{12}$ and Jegadeesh and Titman, ${ }^{13}$ was introduced subsequently, to form the augmented F\&F model.

12 Carhart, M.M. (1997) 'On Persistence in Mutual Fund Performance', Journal of Finance, Vol. 52, pp. 57-82.

13 Jegadeesh, N. and Titman, S. (1993) 'Returns to Buying Winners and Selling Losers: Implications for Stock Market Efficiency', Journal of Finance, Vol. 48, pp. 65-91.

14 Capocci, D. and Hübner, G. (2004) 'Analysis of Hedge Fund Performance', Journal of Empirical Finance, Vol. 11, pp. 55-89.

15 The signs of the factor loadings are seldom discussed in the studies of the F\&F model. This gap must be filled because the signification of these signs is partly a matter of interpretation.

16 On the cause of specification errors, see, for instance, Spencer and Berk. ${ }^{17}$

17 Spencer, D.E. and Berk, K.N. (1981) 'A Limited Information Specification Test', Econometrica, Vol. 49, No. 4, pp. 1079-1085.

18 Durbin, J. (1954) 'Errors in Variables', International Statistical Review, Vol. 22, pp. 23-32.

19 Pal, M. (1980) 'Consistent Moment Estimators of Regression Coefficients in the Presence of Errors in Variables', Journal of Econometrics, Vol. 14, pp. 349-364.

20 Dagenais, M.G. and Dagenais, D.L. (1997) 'Higher Moment Estimators for Linear Regression Models with Errors in the Variables', Journal of Econometrics, Vol. 76, pp. 193-221.

21 Racicot, F.E. (2003) 'On Measurement Errors in Economic and Financial Variables, in Three Essays on the Analysis of Economic and Financial Data. Chapter 3, $\mathrm{PhD}$ thesis. (ESG-UQAM), (published in French).

22 See also: Racicot and Théoret ${ }^{23}$ and Coën et al. ${ }^{24}$
23 Racicot, F.É. and Théoret, R. (2004) 'Numerical calculus in quantitative and empirical finance (Le calcul numérique en finance empirique et quantitative)', $2^{\text {ième }}$ édition. Presses de l'Université du Québec (PUQ), Quebec.

24 Coën, A., Desfleurs, A., Hübner, G. and Racicot, F.E. (2005) 'A Reappraisal of the Performance of Hedge Funds in the Presence of Errors in Variables', in Gregoriou, G. N., Papageorgiou, N., Hübner, G., Rouah, F. (eds.), 'Hedge Funds: Insights in Performance Measurment, Risk Analysis and Portfolio Allocation', John Wiley \& Sons, New Jersey.

25 Samuelson, P.A. (1970) 'The Fundamental Approximation Theorem of Portfolio Analysis in Terms of Means, Variances and Higher Moments', Review of Economic Studies, Vol. 37, pp. 537-542.

26 Rubinstein, M. (1973) 'The Fundamental Theorem of Parameter-Preference Security Valuation', Journal of Financial and Quantitative Analysis, Vol. 8, pp. 61-69.

27 Kraus, A. and Litzenberger, R. (1976) 'Skewness Preference and the Valuation of Risk Assets', Journal of Finance, Vol. 31, pp. 1085-1100.

28 For an empirical test of the n-CAPM, see Dubé et al. ${ }^{29}$ For a general survey about asset pricing models resorting to higher moments, see Jurczenko and Maillet. ${ }^{30}$

29 Dubé, É., Gignac, C. and Racicot, F. (2006) 'Revisiting the Fama and French Model: An Application to Funds of Funds Using Nonlinear Methods', in Gregoriou, G. N. (ed.), 'Fund of Hedge Funds: Performance, Assessment, Diversification and Statistical Properties', Amsterdam, Elsevier.

30 Jurczenko, E. and Maillet, B. (2006) 'Multi-Moment Asset Allocation and Pricing Models', Wiley, New York.

31 Christopherson, J.A., Ferson, W.E. and Glassman, D.A. (1998) 'Conditioning Manager Alphas on Economic Information: Another Look at the Persistence of Performance', Review of Financial Studies, Vol. 11, pp. 111-142.

32 Ferson, W.E. and Qian, M. (2004) 'Conditional Evaluation Performance: Revisited', The Research Foundation of CFA Institute, Virginia.

33 Treynor, J. and Mazuy, K. (1966) 'Can Mutual Funds Outguess the Market', Harvard Business Review, Vol. 44, pp. 131-136.

34 The address of the French's website is: http:// mba.tuck.dartmouth.edu/pages/faculty/ken.french/ data_library.html.

35 Chen, N.F., Roll, R. and Ross, S. (1986) 'Economic Forces and the Stock Market', Journal of Business, Vol. 59, pp. 572-621.

36 LTCM is the acronym of Long Term Capital Management, a highly levered American hedge fund that sustained massive losses in 1998. 
37 For a discussion of the beta and the mean return of option-based strategies, see Whaley, ${ }^{38}$ Chapter 10.

38 Whaley, R.E. (2006) 'Derivatives: Markets, Valuation and Risk Management', Wiley, New York.

39 For each strategy, we selected, in the HFR database, all the funds whose sample begins in January 1997 or before.

40 We will use a noniterated form of the GMM because, according to our previous tests and to a remark done by Chan and Faff, ${ }^{41}$ there is an issue about the reliability of the iterated GMM. Indeed, the $t$-statistics seem boosted in an iterated GMM and the $R^{2}$ are quite low. Besides, the matrix used to weight the moments will be the Newey-West one.
41 Chan, H.W. and Faff, R.W. (2005) 'Asset Pricing and the Illiquidity Premium', Financial Review, Vol. 40, pp. 429-458.

42 Note that there is less difference between the estimation methods when the coefficients are averaged over strategies.

43 SUR for 'seemingly unrelated regressions'.

44 For instance, at the end of the fourth quarter of 2003, the shares of the equity hedge, fund of funds and equity nonhedge strategies in the total assets of the hedge funds were respectively, 29.74, 19.57 and 5.96 per cent. The global share of these three strategies in the total assets of hedge funds was thus about 55 per cent, according to a HFR report. 